\title{
O SOL NA CABEÇA: A ENUNCIAÇÃO LITERÁRIA EM ESPIRAL E AS CENOGRAFIAS PARATÓPICAS NO ESPAÇO DISCURSIVO ÊMICO
}

Izilda Maria NARDOCCI Anderson FERREIRA ${ }^{7}$

\section{Introdução}

Neste capítulo, estudamos o discurso literário O Sol na cabe$c ̧ a^{8}$, livro de contos, escrito por Geovani Martins ${ }^{9}$. Nosso objeti-

7 O presente trabalho foi realizado com apoio da Coordenação de Aperfeiçoamento de Pessoal de Nível Superior - Brasil (CAPES/PNPD) - Número do Processo: 88887.363124/2019-00.

8 O livro O Sol na cabeça é uma coletânea de 13 contos: Rolézim, Espiral, Roleta-russa, O caso da borboleta, A história do Periquito e do Macaco, Primeiro dia, O rabisco, A viagem, Estação Padre Miguel, O cego, O mistério da vila, Sextou, Travessia. Neste trabalho, focalizamos o conto Espiral.

9 Geovani Martins nasceu no Rio de Janeiro em 1991, no bairro de Bangu. Morou na comunidade da Rocinha, Barreira do Vasco e depois no Vidigal. Cursou 
vo é examinar a maneira pela qual a enunciação literária constrói cenografias paratópicas nos espaços tópicos. No interior desses espaços, reunimos enunciados - recortes enunciativos - que revelam estratégias êmicas, conforme a proposta de Bauman (2001). No processo de escritura, utilizamos recortes enunciativos de outros contos do livro em foco, mas para nossa análise, focalizamos o conto Espiral. Para fundamentar teórica e metodologicamente nosso estudo, mobilizamos um quadro interdisciplinar gerido pela Sociologia (BAUMAN, 2001; MACHADO DA SILVA, 2010), pela Antropologia (VITAL DA CUNHA, 2008, 2014) e pela Análise do Discurso (MAINGUENEAU, 1997, 2006; 2008a, 2008b 2010, 2013, 2015, 2016, 2020).

Organizamos o capítulo em quatro seções. Na primeira, "Notas acerca da construção do espaço sociogeográfico na cidade do Rio de Janeiro", ativemo-nos à organização do espaço sociogeográfico da cidade do Rio de Janeiro, tendo em vista as particularidades que o caracterizam; na segunda, "A (des)construção do lugar do outro: violência, medo e insegurança", enfocamos a posição que os sujeitos ocupam nesses espaços que pode ser histórica, ideológica, identitária; na terceira, "Os espaços sociais êmicos", refletimos sobre os espaços sociais êmicos que são marcados por conflitos nem sempre explícitos; na última seção, "As cenografias paratópicas em Espiral, conforme o título já nos orienta, analisamos as cenografias paratópicas do conto Espiral do livro O Sol na cabeça, de Geovani Martins.

apenas o Ensino Fundamental. Começou a trabalhar muito cedo, exercendo diferentes atividades como homem-placa, atendente de lanchonete, garçom em bufê infantil, atendente de barraca de praia. Em 2013 e 2015, participou das oficinas da Festa Literária das Periferias (FLUP). Publicou alguns de seus contos na revista Setor X e, em 2015, foi convidado a participar da programação paralela da FLIP, em Paraty. Em 2017, foi convidado a participar novamente da FLIP, quando assinou contrato com a Companhia das Letras para lançar o seu primeiro livro $\mathrm{O}$ Sol na cabeça. O livro foi vendido para nove países, antes mesmo de sua publicação. 


\section{Notas acerca da construção do espaço sociogeográfico na cidade do Rio de Janeiro}

O Rio de Janeiro é uma metrópole que se caracteriza por uma organização populacional e habitacional bastante peculiar. No núcleo expandido, concentram-se as famílias de maior renda per capita e, também, os recursos urbanísticos mais abundantes. Por sua vez, nas áreas periféricas, concentram-se as famílias de menor renda per capita e a ausência de serviços e infraestrutura básicos. Para a compreensão desse processo de estruturação urbana no Rio de Janeiro, é preciso recuperar as dinâmicas socioeconômicas, políticas e culturais em diferentes momentos (ABREU, 1987), bem como a interação espaço-temporal nas mobilidades dos indivíduos (SANTOS, 2000; BAUMAN, 2001).

No início do século XIX, a cidade do Rio de Janeiro começa a apresentar uma estrutura espacial com diferentes estratos sociais. Nesse período, a maioria da população era de escravos e havia poucos trabalhadores livres. A elite da época, que controlava a política e a economia, era bem reduzida, como observa Abreu (1987).

No decorrer do século XIX, a cidade passa por muitas mudanças. Em 1808, a vinda da família Real faz surgir uma classe social que até então não existia no Rio de Janeiro e, com ela, necessidades materiais para atendê-la. São necessários ainda recursos que facilitem o desempenho das atividades político-econômicas que a cidade passa a exercer. Em 1822, a independência política ${ }^{10}$ e ainda, nesse período, o início da expansão da economia com a produção

10 A Independência política do Brasil foi um processo de separação de Portugal que foi de 1821 a 1825. Em 1820, D. João, em razão de acontecimentos políticos em Portugal, é forçado a retornar à Corte, mas antes nomeia seu filho D. Pedro, Príncipe Regente do Brasil. Como as cortes portuguesas queriam seu repatriamento e que o Brasil voltasse a ser colônia de Portugal, D. Pedro, em 1822, proclama a independência do Brasil. 
de café contribuem para a concentração de muitos trabalhadores livres, nacionais e estrangeiros.

Na segunda metade do século XIX, a cidade passa a atrair capital estrangeiro, empregado no setor de serviços públicos - transporte, esgoto, iluminação a gás, entre outros. Aos poucos a cidade vai passando de uma economia escravista para uma economia capitalista e os conflitos desse movimento vão marcando o espaço urbano. A cidade se desenvolve, pois surgem novos bairros e, neles, são edificados grandes palacetes.

O centro da cidade concentra as casas comerciais de importação e de exportação, e, também, os consulados, bancos, companhias de navegação, entre outras empresas. São implementadas benfeitorias como o calçamento de ruas, iluminação a gás, serviço de esgoto. A população pobre, entretanto, permanece morando no centro, em razão das possibilidades de trabalho que o centro oferece. As moradias populares no centro são os cortiços, insalubres e propícios para epidemias como a da febre amarela, como nos conta o narrador de $O$ Cortiço $^{11}$ :

À proporção que alguns locatários abandonavam a estalagem, muitos pretendentes surgiam disputando os cômodos desalugados. Delporto e Pompeo foram varridos pela febre amarela e três outros italianos estiveram em risco de vida. O número dos hóspedes crescia; os casulos subdividiam-se em cubiculos do tamanho de sepulturas; e as mulheres iam despejando crianças com uma regularidade de gado procriador.

11 Romance de Aluísio de Azevedo. Domínio Público. 
No final do século XIX, as empresas capitalistas - entre elas a Companhia Jardim Botânico que detinha o monopólio dos transportes - com o objetivo de ampliar a utilização de trens e bondes, difundem a ideia de que o estilo de vida "moderno" consistia em residir à beira mar. Dessa forma, a rede de tráfego vai se ampliando, abrindo novos bairros como Copacabana, depois Ipanema e assim por diante. Esses bairros vão sendo ocupados por ricas residências, por aqueles que são, à época, a elite da cidade.

Ao mesmo tempo que as linhas dos bondes avançam, ampliando a região central, as linhas de trem seguem para o subúrbio, juntamente com grande parte da população pobre. Nas margens das linhas férreas e ao redor das estações, essa população, excluída dos espaços purificados, vão construindo, no sentido de Tuan (1983, p. 6), um lugar de segurança num espaço de liberdade - que "começa como espaço indiferenciado e se transforma em lugar à medida que o conhecemos melhor e o dotamos de valor". De fato, com o trem, a população do subúrbio ganha mobilidade. São eles (os trens) que irão reforçar a ideia de valor ao lugar e reduzir o tempo de mobilidade, já que, a fim de ocupar os postos de trabalho no espaço do outro, os trabalhadores e trabalhadoras precisam se deslocar para o centro, onde estão instaladas as indústrias, mas voltam para casa em seus lugares de "segurança".

Além da indústria, caracterizam esse período o fim da escravidão, o declínio da economia cafeeira na Província do Rio de Janeiro e um grande fluxo de imigrantes estrangeiros. Disso resulta um crescimento populacional acelerado, agravando a questão habitacional da cidade e levando a um adensamento populacional ainda maior nos cortiços. A construção de vilas operárias próximas das indústrias é insuficiente para aliviar esse tipo de moradia. 
Nos primeiros anos do século XX, assume a prefeitura da cidade do Rio de Janeiro o engenheiro Francisco Pereira Passos ${ }^{12}$, que implementa um plano de "embelezamento e saneamento da cidade". Trata-se de um programa de reforma urbana que tem o objetivo de transformar a cidade numa verdadeira capital, já que o desenvolvimento que se busca, naquele momento, para o país não combina com uma cidade de aspecto colonial. Pereira Passos desenvolve, então, um plano inédito de intervenção do Estado no espaço urbano.

O processo de renovação da cidade atinge os bairros centrais e os bairros da zona sul. A prefeitura alarga vias, desapropriando prédios, construções que funcionam como cortiços e galpões de trapiches; calça diversas ruas centrais; constrói a avenida beira mar, dando mais acessibilidade à zona sul; reforma praças, onde coloca monumentos para embelezar a cidade; investe na arborização e na jardinagem desses espaços; dá início à construção do Teatro Municipal; proíbe ambulantes e mendicância na região central e na zona sul, entre outras medidas. Tudo isso é feito sem um plano de realocação da população pobre que vive nesses bairros.

As mudanças empreendidas pelo prefeito Pereira Passos no espaço da cidade do Rio de Janeiro dão origem a novas organizações do espaço social e a novas tensões e contradições. Os morros na região central que, até então eram pouco habitados, passam a abrigar moradias populares - a favela. As favelas marcam profundamente a paisagem da cidade no século XX. A população que vai habitar o morro ou o subúrbio é a população pobre, principalmente ex-escravos, que habitam os cortiços e não têm como pagar aluguel na região central, valorizada pelos novos empreendimentos.

12 Francisco Franco Pereira Passos foi um engenheiro e político brasileiro. Nomeado pelo presidente Rodrigues Alves, foi prefeito do então Distrito Federal entre 1902 e 1906. 
No século XX, a cidade passa por muitas transformações, mas segue a configuração iniciada por Pereira Passos, "tanto em termos de aparência (morfologia urbana) como de conteúdo (separação de usos e de classes sociais no espaço)" (ABREU, 1987, p. 70). Embora esforços tenham sido empreendidos em diferentes momentos pelo poder público para acabar com as favelas, o número desse tipo de moradia aumenta significativamente. Segundo o Censo de 2010, há, na região metropolitana do Rio Janeiro, em torno 763 favelas que abrigam $22 \%$ da população.

Houve, portanto, ao longo do século XX, reconfigurações sociogeográficas importantes no espaço social da cidade do Rio de Janeiro, operadas, em particular, pelo gesto político-econômico. Essas reconfigurações constroem demarcações específicas no espaço social urbano; não apenas visual-geográficas, mas histórica-ideológicas que povoam, até hoje, a memória coletiva, social e cultural dos moradores da cidade. Opera-se, dessa maneira, uma separação dos espaços sociais, não apenas efetiva, mas, sobretudo, social e ideológica.

\section{A (des)construção do lugar do outro: violência, medo e insegurança}

Em termos linguístico-discursivos, são evocados itens lexicais como "embaixo" em oposição a "em cima” para designar certa posição clivada dos sujeitos no espaço sociogeográfico. Em geral, são os elementos dêiticos espaciais que designam uma posição histórica, ideológica, identitária, partindo do ponto de referência construído pelo lugar da enunciação. Por exemplo, "lá" se refere a um lugar distante, por sua vez, "aqui" se refere ao espaço onde falam os co-enunciadores (MAINGUENEAU, 2013). Particularmente, o 
vasto campo cultural construído pelo samba carioca, é rico nesse sentido.

Conforme enfatizam os estudiosos no assunto (MÁXIMO; DIDIER, 1990; TINHORÃO, 1998), a partir de Noel Rosa ${ }^{13}$, o samba finalmente desce o morro e conquista o asfalto. A separação espacial será, linguisticamente, marcada no e pelo discurso literomusical.

Alvorada lá no morro, que beleza/Ninguém chora, não há tristeza (Cartola). ${ }^{14}$

Tudo lá no morro é diferente/Daquela gente não se pode duvidar (Beth Carvalho) ${ }^{15}$.

Se vocês estão a fim de prender o ladrão/Podem voltar pelo mesmo caminho/O ladrão está escondido lá embaixo/Atrás da gravata e do colarinho. [....] (Bezerra da Silva $)^{16}$.

Lá no morro quando eu olho pra baixo/Acho a cidade uma beleza/E quando estou na cidade que eu olho pra

13 Noel Medeiros Rosa, compositor brasileiro, nasceu no bairro de Vila Isabel, na Zona Norte carioca, no dia 11 de dezembro de 1910. Noel Rosa teve contribuição fundamental na legitimação do samba de morro e de asfalto, com sua busca de parcerias e diálogo com outros sambistas de sua época. Ele era o elo entre a classe média, a qual pertencia, o morro e o rádio, principal meio de comunicação em sua época.

148 Alvorada. Compositores: Cartola, Carlos Cachaça e Hermínio Bello de Carvalho. In: CARTOLA. Cartola. Disco Sonoro. LP. Produção João Carlos Botezelli (Pelão). Rio de Janeiro: Discos Marcus Pereira, 1974.

15 Linguagem do Morro. Compositores: Padeirinho e Ferreira dos Santos. In: BETH CARVALHO. Brasileira da Gema. CD. Rio de Janeiro: Polygram, 1996.

16 Vítimas da Sociedade. Compositores: Criolo Doido e Bezerra da Silva. In: BEZERRA DA SILVA. Malandro rife. Disco Sonoro. LP. Direção artística Miguel Plopschi. Produção executiva Aramis Barros. Rio de Janeiro: RCA Vik, 1985. 
cima/Fico contemplando a natureza" (Fundo de Quintal) ${ }^{17}$.

Claro que as fronteiras geográficas não são fechadas, mas mecanismos como a especulação imobiliária, o "custo de vida", a renda per capita, o acesso aos meios de transportes e a serviços públicos, no processo de urbanização da cidade do Rio de Janeiro, marcam, por si só, uma diferença para além da geografia sociourbana. Porém, esses mecanismos não são os únicos deflagradores das diferenciações. "Lá", "aqui", “embaixo”, “em cima”, no discurso literomusical acima, recuperam, de alguma forma, tensões linguísticas (LUCCHESI, 2017) ${ }^{18}$, religiosas (VITAL DA CUNHA, 2008, 2014), étnico-raciais (HENRIQUES, 2001), políticas e culturais (ABREU, 1987; MACHADO DA SILVA, 2010), no espaço de mobilidade entre o morro e o asfalto na cidade do Rio de Janeiro.

Além disso, as fraturas políticas, econômicas e sociais são expostas na práxis de se utilizar de estratégicas êmicas no enfretamento da alteridade. Essas estratégias, nos dizeres de Bauman

17 Lá no morro. Compositor: Almir Baixinho. In: GRUPO FUNDO DE QUINTAL. Samba é no Fundo do Quintal, vol. 1. Disco sonoro. LP. Edição histórica, 1980.

18 A respeito dessas "tensões" linguísticas, Dante Lucchesi (2019, p. 371-373) esclarece: "No universo urbano, particularmente no Rio de Janeiro, a segunda metade do século XIX e marcada pelo aprofundamento da normatização linguística, com a criação da cátedra de língua portuguesa no Colégio Pedro II, em 1871; a proliferação das gramáticas normativas, na década de 1880; e a criação, em 1897, da Academia Brasileira de Letras (Faraco 2008: 125-126); tudo isso sob a hegemonia de uma mentalidade purista lusitanizante, que vai perdurar pelas primeiras décadas do século XX, com o Parnasianismo dando o tom da produção literária até a eclosão do Movimento Modernista, em 1922".

[...]. "A urbanização implica a inserção dos largos contingentes urbanizados no mercado consumidor e no universo do letramento. No plano linguístico, isso determina um amplo processo de nivelamento linguístico, no qual a norma urbana de prestígio se impõe aos diversos segmentos sociais, aplainando a antiga diversidade dialetal diatópica". 
(2001, p. 118), consistem em "vomitar, cuspir os outros, vistos como incuravelmente estranhos e alheios". É bem verdade que as paisagens linguístico-geográficas e as memórias afetivas revelam os mapas mentais de cada habitante, mas, quando as linhas geográficas são recortadas por fronteiras sociais, políticas, econômicas, religiosas e/ou étnico-raciais, é preciso que cada um dê sentido ao seu próprio lugar, de forma a legitimar para si uma topia, daí que “Tudo [lá] no morro é diferente". Como diz Bauman (2001, p. 121122 , aspas do autor):

A cidade, como outras cidades, tem muitos habitantes, cada um com um mapa da cidade em sua cabeça. Cada mapa tem seus espaços vazios [vazios de sentido], ainda que em mapas diferentes eles se localizem em lugares diferentes. Os mapas que orientam o movimento das várias categorias de habitantes não se superpõem, mas, para que qualquer mapa "faça sentido", algumas áreas da cidade devem permanecer sem sentido. Excluir tal lugares permite que o resto brilhe e se encha de significado.

Porém, essa exclusão, apontada Bauman (2001), é também inclusão em certo sentido. Com efeito, não se exclui apenas o lugar - a topografia -, mas um outro que, porventura, ocupa esse lugar. Assim, ocorre a exclusão identitária, mas na contemporaneidade, essa exclusão não é radical, por isso inclui-se em outros espaços como no trabalho, no consumo, no entretenimento e produz-se, dessa forma, o lugar como lugar de pertencimento e não pertencimento e o outro como "um corpo saturado de avaliações sociais" (MAINGUENEAU, 2020, p. 84).

Essas sociabilidades se inscrevem na memória social e cultural daqueles que moram na cidade e daqueles que moram nos morros. A arte, o trabalho, a política, a publicidade tentam, cada qual a seu 
modo, produzir nas diferenças, porém as tensões e embates, muitas vezes, são marcados pelas cisões sociais construídas no devir econômico. Não sem efeitos colaterais, as sociabilidades de outrora veem emergir à expansão da violência urbana e do tráfego na cidade do Rio de Janeiro ${ }^{19}$. Em razão da segregação do espaço social, que, segundo Bauman (2001), pode ser "público-mas-não-civil" e da desigualdade social, as condições de violência se desenvolveram e desenvolvem rompendo as fronteiras geográficas, políticas, históricas e ideológicas.

O aumento da violência na cidade do Rio de Janeiro - assim como em outras metrópoles - tem influência direta do tráfico internacional de drogas, o qual encontra, no interior das favelas e subúrbios, novas formas de organização espacial. Nesse cenário, a paisagem pública dos espaços sociais das favelas passa a ser redefinida - em particular, pelo outro - como não lugar, ou lugares vazios (BAUMAN, 2001). Para Machado da Silva (2010, p. 285), essa (des)construção do lugar do outro, afeta "profundamente o entendimento coletivo [desse lugar] na organização urbana”.

Machado da Silva (2010) pondera, contudo, que a construção do não lugar, ou dos lugares vazios de sentido, não é um corolário da conduta ético-moral dos moradores das favelas, isto é, o tráfico de drogas não se apresenta como uma demanda desses moradores, mas ele se beneficia das características espaciais das favelas e da ausência do Estado de bem-estar social. O autor lembra que as linhas de comando da cadeia produtiva de drogas estão longe das favelas. De fato, a localização física da venda de drogas a varejo não se restringe aos espaços urbanos periféricos, mesmo que eles, aos olhos do Estado policial e de parte da sociedade, sejam, muitas vezes, mais visados com relação à dinâmica do tráfico.

19 Não pretendemos reforçar estereótipos, apenas delimitar uma temática para procedermos as análises. 
De qualquer modo, as favelas têm sido uma espécie de base de operações de crimes (MACHADO DA SILVA, 2010), relacionados à venda de drogas. Como nos informa Vital da Cunha (2008, p. 29) em seus estudos, a década de 1990 "foi marcada por uma política de recrudescimento das ações policiais em relação à criminalidade, sobretudo àquela ligada ao tráfico de drogas presente nas favelas cariocas". Se de um lado há, de tempos em tempos, um investimento violento do Estado policial nas favelas, provocando mortes em ambos os lados (FRANCO, 2014), de outro, as práticas de violência interna, incitadas pelas redes de varejo e pelos traficantes em constantes disputas entre si, insuflam as tensões e as dispersam para o asfalto (ou pista). Pelo fato de o funcionamento dos sistemas políticos institucionais que combinam controle e proteção social serem mais frágeis nas regiões de pobreza do que nas demais regiões abastadas da cidade, os mecanismos de venda de drogas nas favelas são mais orgânicos, bem como o "efeito" da violência.

Machado da Silva (2010, p. 286) explica que a violência urbana "articula um complexo de práticas que constituem boa parte do conflito social nas cidades brasileiras". Nesse sentido, não se pode dizer que é paranoia dos moradores, ou mesmo, ficção criada pela mídia jornalística. Para o autor, a noção de violência urbana é a associação do uso de meios violentos com a noção leiga de crime que ameaça constantemente a integridade física e patrimonial das pessoas, não se trata de mero sinônimo de crime violento.

A hipótese do autor é que "a linguagem da violência urbana problematiza uma ordem social específica ou, em outras palavras, reconhece um padrão de sociabilidade que [ele chama de] 'sociabilidade violenta"' (MACHADO DA SILVA, 2010, p. 286). A sociabilidade violenta é o sentido de violência urbana, que se pode observar nas últimas décadas no Rio de Janeiro, bem como em outras grandes centros urbanos. 
[...] é uma forma de vida singular e muito complicada para ser apreendida segundo os modelos disponiveis. Nela, a força física, com ou sem instrumentos e tecnologias, deixa de ser um meio de ação regulado por fins que se deseja atingir, para se transformar em um princípio de coordenação (um "regime de ação") das práticas (MACHADO DA SILVA, 2010, p. 286, ênfases do autor).

Sob essa perspectiva, a violência passa a ter um fim em si mesma, inseparável de sua função instrumental como recurso para a ação. Como sugere o próprio sentido do termo princípio, a violência é sua própria explicação e se autorregula. Na cidade do Rio de Janeiro, os portadores da sociabilidade violenta são, especialmente, os traficantes responsáveis pelo funcionamento dos pontos de venda, localizados nas regiões pobres, conforme nos narra Geovani Martins: ${ }^{20}$

Não vou falar duas vezes que é pra sumir com essa merda desse corpo da minha frente. Papo reto, se alguém der falta desse desgraçado e cair mais um processo nas minhas costas, juro que quem vai pra vala é tu, filho da puta! Agora anda, desaparece, que bandido burro é a pior raça que existe.

Mas a sociabilidade violenta não é exclusividade dos traficantes. Machado da Silva (2010) estabelece uma relação entre o discurso da violência urbana e a atual forma de conflitos de classe. Os conflitos, segundo ele, dado que variam no tempo e no espaço, "são responsáveis pelas variações nas modalidades da integração

20 Travessia (MARTINS, 2018 p. 113). 
social, pois constituem o elemento dinâmico que, nas formações capitalistas, define o Outro e estrutura as relações com ele" (MACHADO DA SILVA, 2010 p. 287). O autor defende, assim, que a emergência da sociabilidade violenta e sua apreensão pela violência urbana, ao menos no Rio de Janeiro, afetou o padrão de sociabilidade até então existente.

As relações com o outro passaram a ser evitadas ao máximo, uma vez que nelas estaria contido o perigo de interrupção das atividades cotidianas. De fato, como coloca Bauman (2001, p. 122), ao discutir o estatuto dos espaços sociais - públicos-mas-não-civis -, "se a proximidade física não pode ser evitada, ela pode pelo menos ser despida da ameaça de "estar juntos" que contém, com seu convite ao encontro significativo, ao diálogo e à interação". Logo, na dimensão simbólica e no plano interpessoal, a relação com o outro se converte em objeto de desconfiança, medo e insegurança (ou violência). A população das regiões pobres é, desse modo, colocada no centro da questão da violência, já que o mapa mental de cada indivíduo é ressignificado pela sociabilidade violenta que paira no tecido social.

A principal característica dos espaços "públicos-mas-não-civis", afirma Bauman (2001), é a dispensabilidade do saber interagir com estranhos, sem usar essa estranheza contra eles. Nessa senda, "o povo" reaparece encarnado no "vizinho diferente" (MACHADO DA SILVA, 2010), com o perigo e a desconfiança envolvidos na relação com o outro. Os "estranhos" são, continuamente, definidos como ameaça à integridade física, psíquica e patrimonial do eu, sem as garantias da continuidade regular das atividades rotineiras. O enfrentamento da alteridade, desse modo, deve ser evitado, mas, quando não é possível, é imperativo lançar mão de estratégias como a antropofágica e a antropoêmica (LÉVI-STRAUSS, 1998). A estratégia antropoêmica, conforme veremos na próxima seção, possibilita a construção de espaços sociais em pleno conflito (CANO, 2012). 


\section{Os espaços sociais êmicos}

Os espaços sociais êmicos, como vimos, são espaços de conflito em que se procura eliminar o outro, pois ele representa uma ameaça. No discurso, os espaços sociais êmicos não estão dados a ver no tecido social, mas eles podem ser isolados pelos analistas, por meio das marcas deixadas nos enunciados. Essas marcas nem sempre são explícitas, tingidas por uma violência verbal numa "manifestação discursiva do preconceito e da intolerância, que já estão consolidados na memória social, cultural e coletiva" (FERREIRA; BENFICA, 2020, p. 1527). Elas estão, ao contrário, apagadas e, muitas vezes, embutidas em gestos indicadores da incapacidade do indivíduo de enfrentar a alteridade. Como nessa passagem do conto de Geovani Martins ${ }^{21}$ :

Os vizinhos quase todos participavam da gira, mesmo os católicos, que frequentavam a missa todo domingo. Mas, como o passar dos anos, o número de pessoas foi diminuindo, enquanto ia crescendo o número de Igrejas na região. O terreiro de nona Iara foi ficando de lado. Muitas vezes até mal-falado pelos antigos frequentadores, depois de convertidos.

De fato, essa forma de enfrentamento da alteridade ocorre nas inter-relações entre os sujeitos no bojo de tensões e embates produzidos nas intersecções das mobilidades identitárias em confrontação histórica. Em consequência, surgem as demandas de afastamento do outro por meio de estratégias antropoêmicas que recusam o enfrentamento da alteridade, segundo Lévi-Strauss (1998). A maneira pela qual se evita a inter-relação social aparece como um rastro sutil desse tipo de estratégia (menos elevada?), que influen-

21 O mistério da vila (MARTINS, 2018, p. 93). 
cia a interrupção das atividades comunitárias. Amiúde, a separação espacial (os subúrbios, a favela, as periferias, o centro, o bairro nobre), a seletividade (o camarote VIP GOLD, o ingresso da área VIP) e o impedimento nos espaços seletivos (a renda per capita individual, o cliente diamante, a pessoa VIP) produzem espaços sociais êmicos modernizados (mais elevados?).

Embora a violência atravesse todo o tecido social, paira a ideia de que ela é natural em certos espaços sociogeográficos, os feios distritos, como explica Bauman (2001). Sem dúvida, trata-se de uma construção histórico-ideológica do espaço, cujos efeitos psicossociais evocam o medo e a insegurança na partição comunitária. Esses efeitos, contudo, não só se materializam na psique social, mas também refletem e refratam, no sentido de Bakhtin e Volóchinovi (2010), as paisagens linguístico-semióticas e geográficas dos espaços ideologicamente construídos.

$\mathrm{Na}$ verdade, os efeitos sociais do medo e da insegurança se materializam na arquitetura geográfico-visual de certos locais; nos mecanismos de segurança dispostos nas ruas, residências e comércios: grades, cadeados, portões de ferro, lanças de vidros em muros, cerca elétrica, sirene de alerta, guarda-noturno, UPPs ${ }^{22}$ entre outros e na e pela linguagem verbo-visual "sobre" e "nesses" espaços sociais. A materialização do medo e da insegurança "sobre" passa, em grande parte, pela construção da notícia (CHARAUDEAU, 2013), pela cobertura da mídia jornalística da criminalidade e da violência (DIAS, 1998). A enunciação literária capta de maneira exemplar esse fenômeno, como em:

22 As UPPs (Unidade de Polícia Pacificadora) é um projeto da Secretaria de Segurança do Estado do Rio de Janeiro que, desde 2008, pretende instituir polícias comunitárias nas favelas. Bastante controverso, esse projeto foi objeto de estudo na dissertação de mestrado da vereadora Marielle Franco, brutalmente assassinada em março de 2018. (Cf. FRANCO, 2014). Esse atentado também ceifou a vida do motorista Anderson Gomes. 
[...] Mataram um boliviano na área, aí os cana tava sofocando na praia, como medo de morrer mais gente, se pá até um morador ou um gringo, e aí ia dar merda braba, tá ligado? Manchete no jornal, Balanço Geral, esses caô ${ }^{23}$.

[...] os polícia sufocando, invadindo casa, esculachando morador por qualquer bagulho. Tá ligado como ele é. Ainda mais com jornal tudo fechando com eles, tinha que ver. Os maluco achava uma pistola entocada, meia dúzia de radinho, pronto, já era primeira página, e vagabundo acreditando que eles ia acabar com o movimento. Tem que ser muito otário, papo reto ${ }^{24 .}$

Por sua vez, a materialização do medo e da insegurança (e do poder!) "nesses" espaços sociais são, também, produzidas pelas paisagens linguístico-semióticas construídas em diferentes conjunturas sociais, conforme nos informa Vital da Cunha (2008, 2014), em suas pesquisas sobre religião e criminalidade na favela do Acari, no Rio de Janeiro ${ }^{25}$.

Conhecedores da dinâmica de ocupação espacial do tráfico nas favelas, os policiais não ignoram a relevância que muros, portões, outdoors têm como instrumentos privilegiados para a comunicação de mensagens, para demarcar posicionamentos, organizar as atividades ro-

23 Rolézim (MARTINS, 2018, p. 14).

24 A história do Periquito e do Macaco (MARTINS, 2018, p. 37).

25 A favela de Acari corresponde a um Complexo formado por sete favelas e um conjunto habitacional. 
tineiras da localidade (como a coleta de lixo etc.), para homenagear os "manos" que morreram e para sugerir (ou impor) a partilha de crenças, valores, linguagens entre moradores e os "donos da rua". Para marcar quais seriam os novos "donos da rua" anunciando, assim, o que seria (ou deveria ser) a nova ordem local, os policiais não só foram os primeiros e principais responsáveis pela destruição das pinturas e altares de santos/entidades na favela, como também usaram os mesmos meios do tráfico - os muros da favela - para se comunicarem (VITAL DA CUNHA, 2014, p. 70).

Nos lugares tomados pelo tráfico no Rio de Janeiro, o medo, a insegurança e a violência dividem espaço com as resistências para o devir. De fato, o enfoque no discurso da violência e do medo produz, muitas vezes, o que Machado da Silva (2010, p. 284) chamou de "efeito boomerang", isto é, "o próprio enquadramento do debate é um dos elementos que reproduz o problema que se quer resolver". Mas somos aqui guiados pela problemática do corpus que construímos (CHARAUDEUA, 2011). Por isso, mesmo atribuindo valor a um lugar, no sentido de Tuan (1983), o produtor do discurso literário pode experimentar a impossível inclusão em um topia (MAINGUENEAU, 2006, 2010). O sentimento de pertencimento e não pertencimento que se apresenta vivo nos territórios de pobreza (NASCIMENTO; CARREIRA, 2012).

Faremos observar que as fronteiras espaciais, históricas e ideológicas da cidade do Rio de Janeiro são atravessadas pela sociabilidade identitária do sujeito do século XXI. Diferente da cisão estético-geográfica marcada no discurso literomusical de certo samba de outrora, o discurso literário de O Sol na cabeça, de Geo- 
vani Martins, explora as paratopias identitária ${ }^{26}$, espacial, temporal (bastante apagada) e linguística integradas no processo criador. Nesse texto, o assento é colocado na paratopia espacial, explorada no conto Espiral, embora essas paratopias são indissociáveis nesse processo. No conto Espiral, em particular, o sujeito, ao mesmo tempo, "se encontra em um lugar que não é o seu [...], se desloca de um lugar para outro sem se fixar [...] [e] não encontra um lugar" (MAINGUENEAU, 2010, p. 161). Porém, esse movimento se dá no interior de uma topia, e nele isolamos um espaço que chamamos de espaço discursivo êmico.

$\mathrm{Na}$ contemporaneidade do século XXI, não se trata mais de ocupar o lugar do outro apenas para o trabalho, o entretenimento, o turismo ecológico, ou mesmo, para o parasitismo de personagens (MAINGUENEAU, 2006), mas de ocupá-lo para pôr à prova as suas estratégicas êmicas: cuspir (os outros); naqueles vistos de parte a parte como incuravelmente estranhos e alheios (BAUMAN, 2001). Essas estratégias podem ser observadas na enunciação literária de $O$ Sol na cabeça, particularmente, no conto Espiral, que, como sugere o título, engendra uma narrativa que se desenrola num plano a partir de um ponto fixo, afastando-se dele de modo gradual. Nesse movimento o co-enunciador-leitor é interpelado pelas cenografias paratópicas que se desdobram no interior dos espaços discursivos êmicos (FERREIRA; FERREIRA; CHAVES, 2018; FERREIRA; BENFICA, 2020) e se inscrevem num tempo "cheio de poeira de outras épocas" (MARTINS, 2018, p. 19). $\mathrm{Na}$ próxima seção, discutiremos a maneira pela qual essas cenografias interpelam os sujeitos envolvidos na enunciação literária em foco.

26 Chaves (2018) defende a noção de paratopia do estigma, argumentando que não há paratopia de identidade. 


\section{As cenografias paratópicas em Espiral}

Cabe lembrar que a estratégia antropoêmica (LÉVI-STRAUSS, 1998) se vale da tentativa de anular a existência física do outro. Para isso, a prisão, a deportação e o assassinato são algumas práticas transseculares (BAUMAN, 2001). Além dessas, dispomos de alternativas "mais contemporâneas", como "a especulação imobiliária, o cliente diamante, a reurbanização das favelas, os condomínios de luxo, [...], que existem para expelir o outro, mas não qualquer outro" (FERREIRA; BENFICA, 2020, p. 1527). A estratégia antropoêmica funda, então, espaços êmicos não compatíveis com os espaços sociogeográficos, mas que são trançados e cimentados no tecido social.

Para o propósito deste trabalho, visamos a examinar essas alternativas (transeculares e contemporâneas) nas cenografias construídas no discurso literário do conto Espiral, de Geovani Martins. Em nosso caso, o texto literário em foco é o "rastro de um discurso em que a fala é encenada" (MAINGUENEAU, 2006). A cena narrativa construída pelo texto, ou seja, a cenografia, conta um momento da vida de um jovem morador de uma favela da Zona Sul, no Rio de Janeiro. Na verdade, a narrativa é construída por cenografias que inscrevem o co-enunciador-leitor na mobilidade sociourbana da cidade do Rio de Janeiro, ou seja, inscreve o leitor no "abismo que marca a fronteira entre o morro e o asfalto na Zona Sul” (MARTINS, 2018, p. 18).

No interior do espaço discursivo êmico que isolamos, é possível observar a inclusão impossível numa topia, para retomar a expressão de Maingueneau (2006; 2010). A ideia de um “impossível lugar” pode ser verificada pela expressão mínima de pertencimento e não pertencimento; "um paradoxo de ordem espacial" (MAINGUENEAU, 2006, p. 110), do qual se intercambiam as cenografias construídas no discurso em análise. As cenografias indicam, então, 
que o enunciador, na e pela enunciação, organiza a maneira pela qual quer enunciar (NARDOCCI, 2020; MAINGUENEAU, 2006, 2008b, 2015). É, portanto, a cenografia como condição e produto da obra, constituída e a constituindo, que são validados os estatutos de sujeitos (enunciador-co-enunciador) espaço (topografia) e tempo (cronografia) (MAINGUENEAU, 1997, 2006, 2008b, 2010, 2015), conforme observamos no discurso abaixo:

\section{$[\text { Recorte 1] }]^{27}$}

[\$1] Começou muito cedo. Eu não entendia. Quando passei a voltar sozinho da escola, percebi esses movimentos. Primeiro com os moleques do colégio particular que ficava na esquina da rua da minha escola, eles tremiam quando meu bonde passava [...]. Andando pelas ruas da Gávea, com meu uniforme escolar, me sentia um desses moleques que me intimidavam na sala de aula. Principalmente quando passava na frente do colégio particular, ou quando uma velha segurava a bolsa e atravessava a rua para não topar comigo. Tinha vezes, naquela época, que eu gostava dessa sensação. Mas como já disse, eu não entendia nada do que estava acontecendo.

A tentativa de anular a presença física do outro pode ser observada no interior do espaço discursivo êmico. Nesse caso, ela toma

27 Nas análises, apresentamos recortes do conto Espiral, que foi tomado como discurso. 
a forma de medo e de poder na interação com outro, isto é, no enfrentamento da alteridade. De um lado, o medo (e poder?) de um outro que tenta anular o contato; "[...] uma velha segurava a bolsa e atravessava a rua para não topar comigo"; por outro lado, o medo e o poder de um outro que se afastou de um grupo (MAINGUENEAU, 2006), a fim de se movimentar num espaço cujo pertencimento e não pertencimento está repleto de tensões histórico-ideológicas. "[...] eles tremiam quando meu bonde passava”.

A paratopia se expressa, assim, num espaço social mais amplo chamado, aqui, de espaço discursivo êmico (FERREIRA, FERREIRA, CHAVES, 2018; FERREIRA; BENFICA, 2020, no prelo), pois, para retomar o termo de Machado da Silva (2010), trata-se de um espaço em que são sedimentadas as sociabilidades violentas. O outro que, ao mesmo tempo, pertence e não pertence a esse espaço (ou grupo), percebe-se num espaço outro, purificado, numa impossível inclusão. No discurso literário em foco, a cenografia paratópica institui o próprio discurso que marca a recusa pelos sujeitos do enfrentamento da alteridade.

Contudo, não se trata de qualquer enfrentamento, ou, para sermos mais específicos, não se trata de qualquer outro. As identidades, aqui, se encontram numa constituição de conflitos sócio-históricos; a imbricação do mesmo e do outro, como enfatiza Maingueneau (2008a), um conflito regulado de onde emergem os posicionamentos. $\mathrm{O} e u$, que narra a história em Espiral, possui vestimentas específicas, "com meu uniforme escolar" e é reconhecido, desde pequeno, como o outro a quem se quer expelir do corpo social: "Começou muito cedo. Eu não entendia". A cenografia paratópica valida e é validada, assim, por sujeitos histórico-ideológicos que se inscrevem em uma sociabilidade violenta (MACHADO DA 
SILVA, 2010, p. 286), o "bonde", isto é, o grupo de amigos da favela, causa medo no outro, num espaço de liberdade (TUAN, 1983). A cronografia e topografias discursivas sedimentam conflitos sociais (ABREU, 1987); étnico-raciais (HENRIQUES, 2001), religiosos (VITAL DA CUNHA, 2008, 2014) e linguísticos (LUCCHESI, 2017).

Os "becos" e as "ruas da Gávea" marcam a fronteira entre o "em cima e o embaixo", entre o "lá" e o "aqui", entre o morro e o asfalto (pista) ${ }^{28}$. Porém, essas topografias discursivas, embora constituam espaços de enunciação (CHAVES, 2018), engendram uma paratopia espacial que expressam a impossível inclusão do enunciador numa topia. O enunciador que, ao percorrer um espaço [social] êmico, não pode senão se surpreender: "eu não entendia nada do que estava acontecendo". A enunciação literária, então, gerida no interior de um espaço discursivo êmico, constitui uma imagem do sujeito histórico-ideológico no posicionamento do enunciador. Assim, a interincompreensão do conflito regulado (medo e poder) relatada pelo enunciador, inscreve o co-enunciador-leitor num espaço social, "mas-não-civil" (BAUMAN, 2001); num "lugar de constituição de sujeitos com suas manifestações de vivências reflexivas e afetivas (NASCIMENTO, 2019, p. 54).

A noção de paratopia proposta por Maingueneau (2006, 2008b, $2010,2015)$ pode se manifestar, segundo esse autor, em dois níveis: no nível do conjunto do discurso constituinte (NASCIMENTO; FERREIRA, 2020) e no nível de cada produtor desse discurso. Nesse último nível, o produtor, visando a uma correspondência com sua enunciação, precisa construir uma impossível identidade, recorrendo, como assinalamos, a formas de pertencimento e não

28 Divisões marcadas na memória social e cultural como vimos no discurso literomusical do samba carioca. 
pertencimento. Essa construção dá conta de cenografias paratópicas não porque a colocamos no interior de espaço discursivos êmicos, mas porque "o rastro deixado pelo texto no discurso" comporta, pelo menos, dois regimes de funcionamento na enunciação literária em foco.

O primeiro regime é enunciativo, ou seja, trata-se da construção de topografias discursivas que "incidem nas formas de interação dos sujeitos aparentes e corroboram com o plano sequencial de acontecimentos que justificam o topoi literário do enunciador" (CHAVES, 2018, p. 127-128): "na esquina da rua da minha escola"; "na nossa própria escola"; nas "ruas da Gávea"; "na frente do colégio particular" [\$1]; "numa favela de Zona Sul”, "outras favelas na Zona Norte, Oeste, Baixada” [\$2]. Essas topografias (espaços) se localizam numa cronografia (tempo) histórico-ideológica: "naquela época" [\$1]; "momento presente" [\$11], em que o ethos do sujeito no discurso se situa no limiar do "posicionamento do enunciador que se diz para propor uma condição a seu favor e uma dimensão ideológica, que exprime normas étnico-sociais, configuradas por eventos vivenciados" (NASCIMENTO, 2019, p. 54).

Entretanto, "é tudo muito próximo e muito distante" [\$2]. De fato, o "lá" e o "aqui" não são apenas um efeito referencial. Para o co-enunciador-leitor, trata-se de uma espécie de armadilha, pois, como enfatiza Nardocci (2020), em diálogo com Maingueneau (2006; 2008b; 2010; 2015, 2016), a cenografia consiste no processo de inscrição, em que estão envolvidos o enunciador-co-enunciador (sujeitos, ethos), um lugar (espaço), um momento (tempo) e um código linguageiro. Abaixo, o enunciador explora essas dimensões. 


\section{Recorte [2]}

[§2] [...]. É foda sair do beco, dividindo com canos e mais canos, o espaço da escada, atravessar valas abertas, encarar os olhares dos ratos, desviar a cabeça dos fios de energia elétrica, ver seus amigos de infância portando armas de guerra, pra depois de quinze minutos estar de frente para um condominio, com plantas ornamentais enfeitando o caminho das grades, e então assistir adolescentes fazendo aulas particulares de tênis. É tudo muito próximo e muito distante. E, quanto mais crescemos, maiores se tornam os muros.

O segundo regime é histórico-ideológico, isto é, a atividade de criação enunciativa é marcada pela sociabilidade identitária do sujeito no mundo contemporâneo do século XXI. Em nosso caso, marcada pela sociabilidade violenta presente na cidade do Rio de Janeiro (MACHADO DA SILVA, 2010). Esses dois regimes estão, intimamente, imbricados, como nos revela o próximo recorte.

\section{Recorte [3]}

[\$3] Nunca esquecerei da minha primeira perseguição. Tudo começou do jeito que eu mais detestava: quando eu, de tão distraído, me assustava com o susto da pessoa e, quando via, eu era o motivo, a ameaça. Prendi a respiração, o choro, me 
segurei, mais de uma vez, pra não xingar a velha que visivelmente se incomodava de dividir comigo, e só comigo, o ponto de ônibus [...]

Embora violenta, a estratégia antropoêmica é legitimada sócio-histórica e culturalmente nas sociedades contemporâneas. $\mathrm{Na}$ verdade, as prisões e as mortes dentro delas são estratégicas transeculares que adentraram o nosso mundo "civilizado", como revela a notícia: "Brasil tem superlotação carcerária de $166 \%$ e 1,5 mil mortes em presídios" 29 . Nos espaços discursivos êmicos, os ditos e os não ditos deixam-se ver num movimento histórico-ideológico que consiste em expelir o outro do corpo social, apagando a sua identidade (FERREIRA, FERREIRA, CHAVES, 2018; FERREIRA, BENFICA, 2020). As tensões de toda ordem, que se inscrevem na memória social, cultural e coletiva dos indivíduos, são capturadas, como já observamos, na enunciação jornalístico-midiática, que encena a violência urbana em sua programação (NASCIMENTO; FERREIRA, 2018, 2019).

A enunciação jornalístico-midiática reproduz, de certa forma, a focalização produzida quando se quer debater acerca da violência e, como argumenta Machado da Silva (2010), os efeitos desse enfoque são perversos, pois criminaliza as populações que moram nas favelas. É fato, porém, que o processo de segregação do espaço social na cidade do Rio de Janeiro, como comentamos no início de nossa discussão, fomentou, de muitas formas, as condições da violência. Rompendo com as fronteiras geográfico-discursivas de outrora ["lá" e "aqui"], ["em cima" e "embaixo"], presenciamos "o crescimento de episódios de violência e seu desborde para áreas antes razoavelmente protegidas" (MACHADO DA SILVA, 2010,

29 Disponível em: https://www.conjur.com.br/2019-ago-22/brasil-lotacao-carceraria-166-15-mil-mortes-presidios. Postado em: 22 ago. 2019. Acesso em: 11 jun.2020. 
p. 284). O recorte a seguir, de certa forma, materializa o espaço segregado historicamente e, nele, os sujeitos históricos.

\section{Recorte [4]}

[\$1] Andando pelas ruas da Gávea, com meu uniforme escolar, me sentia um desses moleques que me intimidavam na sala de aula. Principalmente quando passava na frente do colégio particular, ou quando uma velha segurava a bolsa e atravessava a rua para não topar comigo. Tinha vezes, naquela época, que eu gostava dessa sensação.

[\$3] [...]. Prendi a respiração, o choro, me segurei, mais de uma vez, pra não xingar a velha que visivelmente se incomodava de dividir comigo, e só comigo, o ponto de ônibus. [...]

[\$9] Mário é o nome dele.

[\$11] Chegamos ao momento presente. Passei uns dias rondando um pouco mais de perto sua casa. O que antes era privilégio, morar perto do trabalho, virou um dos seus maiores motivos de preocupação. Ele tentava despistar dando voltas pelos quarteirões, mas seu esforço era inútil, já que há bastante tempo eu sabia onde ficava seu apartamento. 
O "desborde", no entanto, nas cenografias acima construídas, reúne identidades em confrontação histórica. A armadilha na qual o co-enunciador-leitor é pego se deve à exploração exemplar dessas cenografias, em que se associam os sujeitos, uma topografia e uma cronografia. Polos indissociáveis no acesso à cenografia (MAINGUENEAU, 1997), a identidade dos parceiros da enunciação ("eu/a velha" [\$3]; "Mário era o nome dele" [\$9]) encontra-se em sintonia com a definição de um conjunto de lugares ("nas ruas da Gávea, na frente do colégio particular" [\$1]; "no ponto de ônibus" [\$3]) e com momentos da enunciação ("naquela época” [\$3]; "Chegamos ao momento presente" [\$11] ), "a partir dos quais o discurso pretende ser proferido, de modo a fundar seu direito à palavra” (POSSENTI, 2010, p. 20).

É, portanto, no interior dos espaços discursivos êmicos, isolados por nós, que a enunciação literária aqui focalizada produz cenografias paratópicas que se validam e validam essa enunciação por meio da ideia de pertencimento e não pertencimento. A este respeito, ouçamos Maingueneau (2010, p. 161):

Se toda paratopia minimamente expressa o pertencimento e o não-pertencimento, a impossível inclusão em uma "topia", podemos classificar os tipos de paratopia que um produtor de discurso constituinte é suscetível de explorar. A paratopia pode assumir a forma de alguém que se encontra em um lugar que não é o seu, de alguém que se desloca de um lugar para outro sem se fixar, de alguém que não encontra um lugar; a paratopia afasta esse alguém de um grupo (paratopia de identidade), de um lugar (paratopia espacial) ou de um momento (paratopia temporal). 
Maingueneau $(2006 ; 2010)$, quando trata da paratopia espacial, destaca que sua exploração pelo produtor visa a afastar alguém de um grupo; ela pertence, assim, aos exilados, nômades e parasitas. De outro modo, a paratopia espacial pode se manifestar nas sombras da sociedade oficial, como lugares "secretos" nos grandes centros urbanos. Como lembram Salgado e Antas Júnior (2011), a impossível inclusão numa topia, ou num impossível lugar, não significa um lugar inexistente.

Ora, a embreagem "morador de favela", talvez, não tivesse nada de especial se não fosse a maneira pela qual é explorada na enunciação literária em análise. Em nosso caso, o produtor obtém uma situação de inscrição "privilegiada" nas "posições limítrofes, superior ou inferior, da coletividade (MAINGUENEAU, 2010, p. 121, ênfases nossas). Essa situação de inscrição, de certo modo, hibridiza a ideia de superior ou inferior, instaurando [...], ao mesmo tempo, tal posição. A nosso ver, é o espaço discursivo êmico que permite, nas condições sócio-históricas e culturais da cidade do Rio de Janeiro, essa posição ambígua.

O poder de causar "medo" só se efetiva em certos espaços sociais. Uma "posição inferior" pode ser exemplificada no recorte a abaixo:

Recorte [5]

[\$1] Era estranho e até engraçado, porque meus amigos e eu, na nossa própria escola, não metíamos medo em ninguém. Muito pelo contrário, vivíamos fugindo dos moleques maiores, mais fortes, mais corajosos e violentos [...]. 
Porém, a enunciação literária engendra cenografias que validam topografias em plena mobilidade, isto é, a cena muda e interpela o co-enunciador-leitor num jogo "de gato e rato", invertido historicamente.

\section{Recorte [6]}

[§5] Por mais que às vezes me parecesse loucura, sentia que não poderia parar, já que eles não parariam. As vítimas eram diversas: homens, mulheres, adolescentes e idosos. Apesar da variedade, algo sempre os unia, como se fossem todos da mesma família, tentando proteger um patrimônio comum.

[\$2] Ela começou a olhar em volta, buscando ajuda, suplicando com os olhos, [...]. Estava atenta, dura no limite de sua tensão. [...] Por vezes eu aumentava minha velocidade, ia sentindo o gosto daquele medo, cheio de poeira de outras épocas.

Nesse sentido, muda, também, a posição limítrofe. Agora, podemos evocar para o enunciador uma "posição superior", ou seja, o poder de causar medo confunde, mas traz satisfação e uma sensação de revanche. 


\section{Recorte [7]}

[\$4] Passado o turbilhão, fiquei com nojo de ter ido tão longe, lembrando da minha avó, imaginando que aquela senhora também devia ter netos. Porém, esse estado de culpa durou pouco, logo lembrei que aquela mesma velha, que tremia de pavor antes mesmo que eu desse qualquer motivo, com certeza não imaginava que eu também tivera avó, mãe, família, amigos, essas coisas todas que fazem nossa liberdade valer muito mais do que qualquer bolsa, nacional ou importada.

Com efeito, conforme assinala Maingueneau (2006, p. 121), "essas posições têm a particularidade de só ser "posições" entre aspas, uma vez que se configuram como a junção de um território e de forças que escapam a toda tópica social”. Assim, a história contada pela embreagem "morador de favela" ganha destaque porque as tensões e conflitos são reunidos num espaço de segurança, no sentido que colocou Tuan (1983). Por isso, é possível isolar um espaço discursivo êmico, já que é, no interior dessas tensões e conflitos, que os sujeitos têm, diante de si, o dilema do enfrentamento da alteridade.

\section{Conclusão}

Neste capítulo, estudamos o discurso literário O Sol na cabeça, livro de contos, escrito por Geovani Martins, no qual demos des- 
taque para o conto Espiral. Visamos, em particular, examinar de que maneira a enunciação literária em foco constrói cenografias paratópicas nos espaços tópicos. Para tanto, reunimos enunciados - recortes para as análises - que configuram, em nossa opinião, estratégias êmicas, conforme as conceitualizou Bauman (2001). Reunidos dessa forma, esses recortes enunciativos engendram espaços discursivos êmicos, ou seja, espaços de conflitos e de violências sociais em que a presença do outro tende a ser expelida e a identidade apagada (FERREIRA; BENFICA, 2020). Esses espaços foram construídos na e pelas cenografias no desenvolvimento enunciativo.

As análises evidenciaram que as cenografias construídas na enunciação literária, porque situam o lugar paratópico, engendram uma impossível inclusão numa topia. Nesse sentido, seguimos o argumento de Maingueneau (2006, 2008b; 2010) quando ele diz que a paratopia envolve, no mínimo, o pertencimento e o não pertencimento e a inclusão impossível numa topia. Porém, assinalamos que essa impossível inclusão não ocorre apenas pelo desajuste de um sujeito a uma dada cultura, mas, no discurso em análise, ocorre pela estruturação das desigualdades sociais, políticas, jurídicas, econômicas, linguísticas, étnico-raciais e religiosas na sociedade brasileira.

Foi o que observamos quando, o escritor, habilmente, aciona a embreagem "morador de favela" em O Sol na Cabeça. O pertencimento paradoxal do "morador de favela" - sujeito de mobilidade líquida no século XXI - redesenha as topografias discursivas (espaços sociais), de modo ininterrupto, tingindo na enunciação identidades marcadas, ou estigmas, no cenário de tensões históricas transeculares e contemporâneas. Nessa senda, o efeito de sentido de pertencimento e não pertencimento na enunciação literária de O Sol na Cabeça traz consigo o interdiscurso do preconceito, do racismo, da pobreza, da violência, do medo, da insegurança, no 
processo de urbanização na cidade do Rio de Janeiro até os dias de hoje.

Com isso, iluminamos, em nossas análises, a paratopia espacial para argumentar que o efeito de pertencimento e não pertencimento não é apenas um "desajuste" identitário, mas um efeito social marcado historicamente, como argumenta Chaves (2018), um estigma social. Esse efeito paira num lugar tópico, onde a estratégia êmica é, plenamente, legitimada. Daí falarmos de "cenografias paratópicas", sabendo que as cenografias não são por si só paratópicas. Elas interpelam o co-enunciador-leitor por meio do efeito da inadequação entre um lugar dotado de valor e um sujeito-histórico. É, portanto, no interior dessa inadequação, entre os sujeitos e o lugar (topografia), que os tipos de paratopia se manifestam.

A consideração que fizemos a respeito da embreagem "morador de favela" tinha como pretensão mostrar que essa identidade carrega historicamente uma marca de valoração negativa, ou, para usar os termos de Chaves (2018), inscreve no e pelo discurso uma paratopia do estigma. Nas palavras deste autor, os estigmas são

[...] elementos negativos que associados a determinados sujeitos ou grupos, interferem na construção da identidade desses grupos ou sujeitos. Esses elementos são compostos como imaginários socioculturais e, quando acoplados a uma identidade, trarão efeito negativo, justificado por esse imaginário. Podemos supor que, toda identidade que precisa relatar a si mesma, carrega de certo modo, um destes imaginários, um estigma. Para alguns sujeitos, bastará compor a sua fachada de acordo com as exigências de um cenário. Entretanto, essa facilidade não acontecerá para todos os sujeitos indiscrimina- 
damente. Há sujeitos que terão como marca, quer física, quer comportamental, quer de qualquer outra natureza, algo que não pode ser entendido como natural do espaço (CHAVES, 2018, p. 62-63).

Nesse espaço construído pela enunciação literária de $O$ Sol na Cabeça, e, em particular, de Espiral, a embreagem "morador de favela" carrega esses "imaginários", que não cabem num lugar. Porém, não se trata de "um lugar afastado do mundo cotidiano" (MAINGUENEAU, 2006, p. 129): uma montanha, uma tribo, uma ilha; mas, no caso em análise, de um lugar no interior da cidade, isto é, de um lugar que ressignifica as fronteiras sociais, econômicas e culturais da cidade do Rio de Janeiro. Esse lugar é possível porque é possível a mobilidade do sujeito "morador de favela", no século XXI. Contudo, porque organizado em torno dessa embreagem, a inclusão nesse lugar se torna impossível.

Mas a favela, também, aparece como problemática para o autor que se enuncia por meio do pertencimento paradoxal do morador de favela. O escritor carrega a legitimidade do literato e, ao mesmo tempo, o estigma do favelado: meu lugar não é meu lugar. $\mathrm{Na}$ favela, o escritor é mais um morador, por sua vez, nos lugares institucionais da literatura, ele é um escritor "morador de favela". É como afirma Antonio Prata na orelha do livro "vai chegar um dia em que a orelha de um livro de Geovani Martins poderá ignorar o fato de que ele é um escritor nascido em Bangu e morador da Rocinha ou do Vidigal".

Mas esse dia ainda não chegou e a enunciação literária de Espiral joga, de modo muito feliz, com isso, pondo em cena o morador da favela para fazer ranger as cisões nos espaços em que ele circula, como na passagem que analisamos no recorte [2] e que, aqui, retomamos: 
[\$2] [...]. É foda sair do beco, dividindo com canos e mais canos, o espaço da escada, atravessar valas abertas, encarar os olhares dos ratos, desviar a cabeça dos fios de energia elétrica, ver seus amigos de infância portando armas de guerra, pra depois de quinze minutos estar de frente para um condomínio, com plantas ornamentais enfeitando o caminho das grades, e então assistir adolescentes fazendo aulas particulares de tênis. É tudo muito próximo e muito distante. E, quanto mais crescemos, maiores se tornam os muros.

Nessa senda, a embreagem "morador de favela" engendra um duplo não pertencimento. De um lado, ele não pertence à favela, no sentido de não se inscrever em uma sociabilidade violenta (MACHADO DA SILVA, 2010); de outro, ele não pertence à cidade, já que nesses espaços a estratégia êmica possui um exército em campanha. Por isso, em ambos os espaços, a embreagem "morador de favela" desencadeia tensões e conflitos. O co-enunciador-leitor se confronta com as cenografias paratópicas de tensões e conflitos, que, se bem compreendidos, estão marcados e sedimentados no social, no histórico e no cultural.

Esse estudo, ainda em andamento, pretendeu contribuir com a discussão em torno da categoria de paratopia, conforme apresentada por Maingueneau (2006, 2008b, 2010, entre outros). Embora este autor enfatize que "toda paratopia pode ser reduzida a um paradoxo de ordem espacial" (MAINGUENEAU, 2006, p. 110 ), acreditamos ter explorado de modo mais amplo essa condição na enunciação literária por nós focalizada. Supomos, de outro modo, que a construção de um espaço discursivo êmico permitiu 
enlaçar as condições sócio-históricas e culturais do Rio de Janeiro em seu processo de reurbanização, no começo do século XX (ABREU,1987), com o espaço fronteiriço entre o morro e o asfalto (VITAL DA CUNHA, 2008, 2014; MACHADO DA SILVA, 2010).

Por fim, reproduzimos as palavras de Antonio Prata a respeito do discurso literário de Geovani Martins que capta com propriedade os efeitos sociais gerados pela fronteira entre o "embaixo" e "em cima” e o entre o "lá" e o "aqui".

Neste primeiro livro, [...] a inspiração autobiográfica é clara, e a força dos contos é inseparável do lugar de onde o autor vê o mundo. Nos treze textos de O Sol na cabeça, acompanhamos a infância e a adolescência de garotos para quem as angústias e dificuldades próprias da idade somam-se à violência de crescer no lado menos favorecido da 'Cidade partida ${ }^{30}$, o Rio de Janeiro das primeiras décadas do século XXI" (Antonio Prata, orelha do livro).

\section{Referências}

ABREU, José Maurício. Evolução urbana do Rio de Janeiro. Rio de Janeiro: Jorge Zahar Editor, 1987.

AZEVEDO, Aluísio. O cortiço. 30. ed. São Paulo: Ática, 1997. (Bom Livro). Disponível em: http://www.dominiopublico.

30 Cidade Partida é o título de obra de Zuenir Ventura que trata da violência nas favelas do Rio de Janeiro. 
gov.br/download/texto/bv000015.pdf. Acesso em: 24 jun. 2020 .

BAUMAN, Zygmunt. A modernidade líquida. Tradução Plínio Dentzien. Rio de Janeiro: Jorge Zahar, 2001.

BAKHTIN, Mikhail; VOLOCHÍNOV, Valentin Nikolaevich. Marxismo e filosofia da linguagem. Ed. 14. São Paulo: Hucitec, 2010 .

CANO, Márcio Rogério de Oliveira. A manifestação dos estados de violência do discurso do jornalismo. 2012. $167 \mathrm{f}$. Tese (Doutorado em Língua Portuguesa) - Programa de Estudos Pós-Graduados em Língua Portuguesa, Pontifícia Universidade Católica de São Paulo, São Paulo, 2012.

CHARAUDEAU, Patrick. "Dize-me qual é teu corpus, eu te direi qual é a tua problemática”. Revista Diadorim / Revista de Estudos Linguísticos e Literários do Programa de Pós-Graduação em Letras Vernáculas da Universidade Federal do Rio de Janeiro. Volume 10, Dezembro, 2011.

CHARAUDEAU, Patrick. O discurso das mídias. 2.ed. 2a reimpressão. Tradução Ângela S.M. Corrêa. São Paulo: Contexto, 2013.

CHAVES, Ramon Silva. A paratopia do estigma: identidade e relato de si no discurso Recordações do Escrivão Isaías Caminha, de Lima Barreto. 2018. $201 \mathrm{f}$. Tese (Doutorado em Língua Portuguesa) - Programa de Estudos Pós-Graduados em Língua Portuguesa, Pontifícia Universidade Católica de São Paulo, São Paulo, 2018.

DIAS, Ana Rosa Ferreira. O discurso da violência: as marcas da oralidade do jornalismo popular. São Paulo: Cortez, 1998.

FERREIRA, Anderson; FERREIRA, Cristiane da Silva; CHAVES, Ramon Silva. As práticas discursivas da violência nas mídias digitais: Marielle Franco, presente... no espaço discursivo êmico. (Con)Textos Linguísticos, v. 2, p. 59-78, 2018. 
FERREIRA, Anderson; BENFICA, Samine de Almeida. A violência verbal em manifestações explícitas de preconceito linguístico no Facebook: um espaço discursivo êmico. Rev. Estud. Ling., Belo Horizonte, 2020, p. 1519-1549.

FRANCO, Marielle. UPP: A redução da favela a três letras: uma análise da política de segurança pública do Estado do Rio de Janeiro. Dissertação apresentada ao Programa de Pós-Graduação em Administração da Faculdade de Administração, Ciências Contábeis e Turismo da Universidade Federal Fluminense, 2014.

HENRIQUES, Ricardo. Desigualdade racial no Brasil: evolução das condições de vida na década de 90. Instituto de Pesquisa Econômica Aplicada (IPEA), 2001.

LÉVI-STRAUSS, Claude. Tristes Trópicos. Tradução de Rosa Freire D’Aguiar. São Paulo: Companhia das Letras, 1998.

LUCCHESI, Dante. A periodização da história sociolinguística do Brasil. D.E.L.T.A., 33.2, 2017, 347-382.

MACHADO DA SILVA, Luiz Antonio. "Violência urbana”, segurança pública e favelas - $\mathrm{O}$ caso do Rio de Janeiro atual. In: Caderno CRH, Salvador. V. 23, n. 59, p. 283-300. Maio/ Agosto, 2010.

MAINGUENEAU, Dominique. Novas tendências em Análise do Discurso. 3.ed. Tradução Freda Indursky. Campinas, SP: Pontes: Universidade Estadual de Campina, 1997.

MAINGUENEAU, Dominique. Discurso Literário. Tradução Adail Sobral. São Paulo: Contexto, 2006.

MAINGUENEAU, Dominique. Gênese dos discursos. Tradução Sírio Possenti. São Paulo: Parábola, 2008a.

MAINGUENEAU, Dominique. Cenas da enunciação. Sírio Possenti e Maria Cecília Péres Souza-e-Silva (orgs.). São Paulo, Parábolas, 2008b. 
MAINGUEnEAU, Dominique. Doze conceitos em análise do discurso. São Paulo: Parábola, 2010.

MAINGUENEAU, Dominique. Análise de textos de comunicação. 6. ed. ampl. Tradução Cecília P. de Souza e Décio Rocha. São Paulo: Cortez, 2013.

MAINGUENEAU, Dominique. Discurso e análise do discurso. Tradução Sírio Possenti. São Paulo: Parábola, 2015.

MAINGUENEAU, Dominique. Retorno crítico sobre o ethos. In: BARONAS, Roberto Leiser; MESTI, Paula Camila; CARREON, Renata de Oliveira (orgs.). Análise do Discurso: entorno da problemática do ethos, do político e de discursos constituintes. Campinas, SP: Pontes, 2016.

MAINGUENEAU, Dominique. Variações sobre o ethos. Tradução Marcos Marcionilo. São Paulo: Parábola, 2020.

MARTINS, Geovani. O Sol na cabeça. São Paulo: Companhia das Letras, 2018.

MÁXIMO, João; DIDIER, Carlos. Noel Rosa: uma biografia. Brasília: Editora Universidade de Brasília, Linha Gráfica Editora, 1990.

NASCIMENTO, Jarbas Vargas; CARREIRA, Rosângela Aparecida Ribeiro. Uma análise do discurso da guerra em Moçambique e o papel social da leitura nas camadas interdiscursivas de Terra Sonâmbula. Linha d’Água, n. 26 (1), p. 67-82, 2013.

NASCIMENTO, Jarbas Vargas. Em torno do ethos discursivo e de questões de identidade. In: FERREIRA, L. A. (org.). Inteligência retórica: $o$ ethos. São Paulo: Blucher, 2019, pp. 45 -62 .

NASCIMENTO, Jarbas Vargas; FERREIRA, Anderson. Discurso e Cultura. Volume 1. São Paulo: Blucher, 2018.

NASCIMENTO, Jarbas Vargas; FERREIRA, Anderson. Discurso e Cultura. Volume 2. São Paulo: Blucher, 2019. 
NASCIMENTO, Jarbas Vargas; FERREIRA, Anderson. Discursos Constituintes. São Paulo: Blucher, 2020.

NARDOCCI, Izilda Maria. Vlog: Nova Prática Discursiva na mídia. Revista Caminhos em Linguística Aplicada, 2020, no prelo.

POSSENTI, Sírio. Ler, descrever e interpretar. In: SERRANI, Silvana (org.). Letramento, discurso e trabalho docente. Vinhedo: Editora Horizonte, 2010, pp. 14-28.

SANTOS, Milton. Por uma outra globalização: do pensamento único à consciência universal. Rio de Janeiro: Record, 2000.

SALGADO, Luciana Salazar; ANTAS JÚNIOR, Ricardo Mendes. A criação num "mundo sem fronteiras": paratopia no período técnico-científico informacional. Acta Scientiarum. Language and Culture. Maringá, v. 33, n. 2, p. 259-270, 2011.

TINHORÃO, José Ramos. História social da música popular brasileira. São Paulo: Ed. 34,1998.

TUAN, Yu-Fu. Espaço e lugar: a perspectiva da experiência. Tradução Lívia de Oliveira. São Paulo: DIFEL, 1983.

VITAL DA CUNHA, Christina. “Traficantes evangélicos”: novas formas de experimentação do sagrado em favelas cariocas. PLURAL, Revista do Programa de Pós-graduação em Sociologia da USP, São Paulo, v.15, 2008, pp. 23-46.

VITAL DA CUNHA, Christina. Religião e criminalidade: traficantes e evangélicos entre os anos 1980 e 2000 nas favelas cariocas. Religião e Sociedade, v. $34 \mathrm{n}^{\circ} .1$, Rio de Janeiro: June, 2014, pp. 2-20. 